\title{
Uma leitura deleuziana da Estética Transcendental
}

Vagner Silva

Mestre em filosofia e doutorando em Filosofia da Educação

\section{Resumo}

O artigo mostra como é possível utilizar conceitos filosóficos (no caso o conceito de filosofia de Deleuze e Guatarri) como categorias de análise dentro da própria filosofia. Para isso se analisa o conceito de Conceito, proposto por Deleuze/Guatarri e seus correlatos e em seguida se averigua a compatibilidade entre a proposta dos filósofos franceses do que é filosofia com a Estética Transcendental, parte da obra Crítica da razão pura de Kant, constatando que de acordo com os critérios propostos pelos pensadores franceses é possível considerar o texto kantiano como o mais legítimo texto filosófico.

Palavras chave: Conceito, Estética transcendental, Deleuze.

\begin{abstract}
The article shows how it is possible to use philosophical concepts (in the case the concept of philosophy of Deleuze and Guatarri) as analysis categories inside of the own philosophy. For that the concept of Concept proposed by Deleuze/Guatarri is analyzed, and other related concepts and soon afterwards it is checked the compatibility between the French philosophers' proposal of what philosophy is with the Transcendental Aesthetics, part of the book Critic of the pure reason of Kant, verifying that in agreement with the criteria proposed by the French thinkers it is possible to consider the kantian text as the most legitimate philosophical text.
\end{abstract}

Key words: Concept, Transcendental Aesthetics, Deleuze. 
Introdução

$\mathrm{E}$ ste trabalho tem dois objetivos principais: o primeiro, como fica claro pelo seu título, é fazer uma leitura da Estética Transcendental de Kant, partindo da filosofia de Gilles Deleuze, e mostrar que de acordo com a conceituação deste filósofo do que é filosofia, podemos perfeitamente enquadrar o trabalho de Kant como um perfeito trabalho filosófico.

Este objetivo parece bastante tolo, pois poucos duvidariam do fato de Kant ser um filósofo, logo tal demonstração parece desnecessária. Aqui entra o segundo objetivo deste trabalho: mostrar que também é possível lidar com a filosofia sem ser filósofo, sendo apenas um professor de filosofia, ou mesmo um técnico no assunto. Este, pois, será o segundo objetivo do trabalho. Inegavelmente também será interessante um diálogo entre dois filósofos tão distintos, em especial este diálogo será uma espécie de demonstração deleuziana do que é a filosofia, e como ela é tecida a partir de uma tríade teórica elaborada por Deleuze: os conceitos, o plano de imanência e os personagens conceituais.

\section{O que é filosofia?}

Embora esta pergunta já aparente certa vulgaridade, após 2500 anos de tradição filosófica, me parece impossível começar um trabalho como este sem ser por ela. Responder tal questão será fundamental para alcançar o primeiro objetivo deste trabalho (mostrar que a Estética Transcendental, pode, perfeitamente, ser vista como filosofia, segundo a conceituação deleuziana de filosofia).

Em Diferença e Repetição Deleuze afirma que:

Há de tudo na Crítica, um tribunal de juiz de paz, um cartório de registros, um cadastro - salvo a potência de uma nova política que subverteria a ima- 
gem do pensamento. Mesmo o Deus morto e o $E u$ rachado são apenas um mau momento a passar, o momento especulativo; eles ressuscitam, mais integrados e certos do que nunca, mais seguros de si mesmos, mas num outro interesse, no interesse prático ou moral. (Deleuze, 2006, p. 200).

E se Deleuze faz tais observações sobre o pensamento de Kant é porque antes já vinha acusando a Crítica de incapacidade para mudanças, de incapacidade de assustar, de incapacidade de fazer mal, e o "que é um pensamento que não faz mal a ninguém, nem àquele que pensa, nem aos outros?" (Deleuze, 2006, p. 198):

Nota-se a que ponto a Crítica kantiana é finalmente respeitosa: nunca o conhecimento, a moral, a reflexão, a fé, são postos em questão, presumindose em sua correspondência interesses naturais da razão, mas somente o uso das faculdades, que é declarado legítimo ou não de acordo com este ou aquele desses interesses. (Deleuze, 2006, p. 200).

Mas se em Kant há, de um tribunal filosófico bastante clemente e compreensivo, até a apatia filosófica; somos obrigados a admitir que nele também há todos os elementos, apontados por Deleuze e Guattari ${ }^{1}$, que constituem a filosofia: o conceito, o plano de imanência e os personagens conceituais.

\section{Os Elementos da filosofia}

\section{O Conceito}

Para Deleuze e Guattari a filosofia se define pela sua capacidade criadora. Mas o que cria a filosofia não é qualquer coisa, o que ela cria as outras disciplinas do conhecimento humano não criam - conceitos. Não posso deixar de fazer alusão a uma idéia do filósofo alemão Friedrich Nietzsche, de que a filosofia deve ser a má consciência de seu tempo. Que fique claro contra

1 Ver: Deleuze, Gilles e Guattari, Félix. O que é a Filosofia? Trad. Bento Prado Jr. e Alberto Alonso Muñoz. Rio de Janeiro: Ed. 34, 1992.

(C) Filosofia e Educação (Online), ISSN 1984-9605 - Revista Digital do Paideia 
quem Deleuze filosofa, contra quem ele lança sua teoria, de quem ele se faz má consciência: contra todos aqueles que afirmam ser a filosofia alguma espécie de reflexão, uma contemplação, ou comunicação

Ela não é reflexão, porque ninguém precisa de filosofia para refletir sobre o que quer que seja: acredita-se dar muito à filosofia fazendo dela a arte da reflexão, mas retira-se tudo dela [...]. A filosofia não contempla, não reflete, não comunica, se bem que ela tenha de criar conceitos para estas ações ou paixões. (Deleuze e Guattari, 1992, pp. 14-5).

Porém se a filosofia é a criação de conceitos, conceituar os conceitos será sem dúvida o ponto mais difícil deste trabalho. Em especial se estamos habituados com conceitos que são, na verdade definições. A abordagem de Deleuze e Guattari no livro acima citado ( $O$ que é a filosofia?) é bastante interessante: os filósofos sabiam da gravidade e dificuldade de sua empreitada, sabiam que se dissessem: "O conceito é isso", ou "O conceito $e ́$ aquilo", o pequeno verbo de ligação os trairia, pois um conceito não é uma definição e também não é aquilo que se diz dele, pois o conceito é sempre mutante.

Se afirmo que o conceito de bem "é o cumprimento da lei moral", fechei o conceito de bem de tal forma, que dentro dele não cabe mais nada. Pois logicamente uma coisa não pode ser coisas distintas simultaneamente, e ainda que tenha que explicar, no exemplo acima, o que é a lei moral, o conceito de bem já está terminantemente perdido, dele não se pode extrair mais nada. Um conceito deste tipo mais imobiliza o pensamento que o permite avançar e devir,

[...] um conceito tem sempre componentes que podem impedir a aparição de um outro conceito, ou, ao contrário, que só podem aparecer ao preço do esvanecimento de outros conceitos. Entretanto, nunca um conceito vale por aquilo que ele impede: ele só vale por sua posição incomparável e sua criação própria. (Deleuze e Guattari, 1992, p. 44) 
Não podendo e não querendo definir o conceito, os filósofos o conceituam a partir de sua função e formação. Relutei muito em utilizar a palavra função, pois se um conceito tiver uma função pré-definida, é um imobilizador do pensamento, é um conceito fechado. Que ela então não seja compreendida inadequadamente: função aqui indica aquilo para o que os conceitos de um modo geral servem, e para o que são sempre usados: compreensão, formulação e resolução de problemas:

Todo conceito remete a um problema, a problemas sem os quais não teria sentido, e que só podem ser isolados ou compreendidos na medida de sua solução: estamos aqui diante de um problema concernente à pluralidade dos sujeitos, sua relação, sua apresentação recíproca. (Deleuze e Guattari, 1992, pp. 14-5).

Eis o primeiro ponto para a compreensão do que são os conceitos: sua função. Os conceitos são criados para solucionar problemas. Todavia muitos problemas ainda não são claros, ainda não foram bem colocados, bem explicados e bem entendidos. Os conceitos não servem apenas para resolver problemas, mas também para criá-los, para clareá-los, e para definilos.

Em um momento de rara honestidade filosófica ${ }^{2}$ Nietzsche, explicando seu roteiro de trabalho em seu livro A Genealogia da Moral mostra de que modo trabalha com os conceitos, para esclarecer os problemas, compreendê-los, e claro, buscar resolvê-los:

[...] sob que condições o homem inventou para si os juízos de valor "bom" e "mau"? e que valor têm eles? Obstruíram ou promoveram até agora o crescimento do homem? São indício de miséria, empobrecimento, degeneração da vida? Ou, ao contrário, revela-se neles a plenitude, a força, a von-

\footnotetext{
2 Nietzsche sempre fez questão de deixar claro que escondia seus pensamentos para que não fossem entendidos por todos. Por isso, aqui falo em rara honestidade, o filósofo sempre optou por esconder seus pensamentos mais profundos dentro de labirintos aforísticos, de anedotas e até mesmo de discursos sobre culinária.
}

(C) Filosofia e Educação (Online), ISSN 1984-9605 - Revista Digital do Paideia 
tade da vida, sua coragem, sua certeza, seu futuro? - Para isso encontrei e arrisquei respostas diversas, diferenciei épocas, povos, hierarquias dos indivíduos, especializei meu problema, das respostas nasceram novas perguntas, indagações, suposições, probabilidades: até que finalmente eu possuía um país meu, um chão próprio, um mundo silente, próspero, florescente, como um jardim secreto do qual ninguém suspeitasse... [destaques meus] (Nietzsche, 1998, p. 9).

Nas primeiras linhas do texto acima o filósofo alemão põe o problema: a moral (representada pelos conceitos "bom" e "mau"). A questão a se resolver: saber de que modo a moral agiu no ser-humano até agora, se o engrandeceu ou o fez diminuir. E depois o modo, como através de uma intensa criação conceitual o filósofo prosseguiu em seu intento. Nota-se pelas palavras destacadas o esmero filosófico-conceitual: "diferenciei épocas, povos, (...) especializei meu problema, das respostas nasceram novas indagações (...) até que finalmente eu possuía um país meu, um chão próprio..." Percebemos a partir de Nietzsche a função dos conceitos; especializando o problema, tornando problemático o que até então não era, para só então buscar uma resposta, com a clarividência de que destas soluções surgem sempre novos problemas.

Os conceitos porém não têm apenas uma função, têm também uma formação. Podemos dizer, seguindo Deleuze, que a formação dos conceitos é histórica e relacional, ou seja, os conceitos não surgem, como se fossem um fenômeno necessário de alguma coisa em si ou de alguma idéia pura. Os conceitos são criados a partir de redes conceituais, agrupam-se a outros conceitos. Muitos destes conceitos, ou melhor, as palavras que os representam, já existem, e o que cada filósofo faz é dar-lhes outro(s) sentido(s) diferente(s) do sentido anterior.

Podemos ver isso claramente na maneira como o próprio Deleuze transforma o conceito nietzscheano de eterno retorno do mesmo, transformando-o em um eterno retorno apenas, sem o mesmo. Um retorno que se torna seletivo, um retorno que, ao contrário do que se dá em Nietzsche, su-

(C) Filosofia e Educação (Online), ISSN 1984-9605 - Revista Digital do Paideia 
prime o que é fraco e degenerado. Deleuze não estaria então, apenas se apoderando de um conceito já existente? Sim, claro. Porém este apoderar-se ressignificando também é criar.

Um conceito não exige somente um problema sob o qual remaneja ou substitui conceitos precedentes, mas uma encruzilhada de problemas em que se alia a outros conceitos coexistentes [...]. Em primeiro lugar, cada conceito remete a outros conceitos, não somente em sua história, mas em seu devir ou suas conexões presentes. Cada conceito tem componentes que podem ser, por sua vez, tomados como conceitos [...]. Os conceitos vão, pois, ao infinito, e, sendo criados, não são jamais criados do nada. (Deleuze e Guattari, 1992, pp. 30-1).

Sem dúvida é difícil compreendermos o que são os conceitos, e ainda assim mantê-los abertos e amplos, propícios ao pensamento. Porém Deleuze nos oferece uma idéia de conceito que facilita sua compreensão, ou ao menos nos permite avançar alguns centímetros: o conceito como um rasgo no caos, ou como prefiro dizer, como áreas e/ou regiões de colonização do caos. O conceito interfere sobre o caos permitindo uma ordenação do mesmo, permitindo fundar sobre um pântano de areias movediças alguma realidade, como afirma Gallo:

[...] a criação de conceitos é, necessariamente, uma intervenção no mundo, ela é a própria criação de um mundo. Assim, criar conceitos é uma forma de transformar o mundo; os conceitos são ferramentas que permitem ao filósofo criar um mundo à sua maneira. (Gallo, 2003, p. 41).

A idéia do conceito como colonização do caos, criando novas realidades, é bastante adequada ao pensamento do filósofo francês, mas também podemos recorrer ao berço da filosofia para vermos como faz sentido esta idéia. Para os gregos o kháos não era apenas a imensidão do tempo e do espaço, era também a ausência de ordem e sentido, começo e fim de tudo o 
que existe. $\mathrm{O}$ vocábulo grego que se opunha a caos era logos, que não representava por sua vez apenas a ordem, e a definição dos espaços e do tempo, mas também a razão, o senso, e a linguagem, que possibilita os elementos anteriores, e que não pode prescindir das palavras, a partir das quais os conceitos também são formados.

\section{O Plano de Imanência}

Um segundo elemento componente da filosofia é o plano de imanência, ele é o chão sobre o qual se enraízam e crescem os conceitos. Todavia "é essencial não confundir o plano de imanência e os conceitos que o ocupam" (Deleuze e Guattari, 1992, p. 55). O plano de imanência é pré-conceitual, Deleuze disse mesmo que é pré-filosófico, ele é a abertura e nomeação de mundo necessárias para que a filosofia comece com seus conceitos.

Heidegger, falando sobre a abertura de mundo que os poetas e escritores criam para iniciar seu poetar elaborou o conceito de Lichtung (clareira). A idéia é que cada poeta, cada escritor, ao iniciar sua obra abre uma clareira no mundo. Como se o mundo fosse uma grande e densa selva, na qual o poetar funda uma realidade simplesmente ao dizer-se. O perfeito exemplo disso encontramos em Guimarães Rosa, em seu Grande Sertão: veredas. Quando no início do livro é dita a primeira palavra "nonada", o que se tem é uma nomeação de mundo, a criação de uma Lichtung, o mesmo quando no primeiro parágrafo de Cem Anos de Solidão, García Marques descreve Macondo. Se falássemos de filosofia, Macondo e nonada seriam planos de imanência. Seriam os "espaços" pré-filosóficos nos quais os conceitos surgem e se enraízam.

Se a filosofia começa com a criação de conceitos, o plano de imanência deve ser considerado como pré-filosófico. Ele está pressuposto, não da maneira pela qual um conceito pode remeter a outros, mas pela qual os conceitos remetem eles mesmos a uma compreensão não-conceitual. Esta compreensão intuitiva varia ainda segundo a maneira pela qual o plano está traçado [...]. Pré-filosófica não significa nada que preexista, mas algo que

(C) Filosofia e Educação (Online), ISSN 1984-9605 - Revista Digital do Paideia 96 
não existe fora da filosofia, embora esta o suponha. São suas condições internas. O não-filosófico está talvez mais no coração da filosofia que a própria filosofia, e significa que a filosofia não pode contentar-se em ser compreendida somente de maneira filosófica ou conceitual, mas que ela se endereça também, em sua essência aos não-filósofos [...]. A filosofia é ao mesmo tempo criação de conceito e instauração do plano. O conceito é o começo da filosofia, mas o plano é sua instauração. O plano não consiste evidentemente num programa, num projeto, num fim ou num meio; é um plano de imanência que constitui o solo absoluto da filosofia, sua Terra ou sua desterritorialização, sua fundação, sobre os quais ela cria seus conceitos. Ambos são necessários, criar os conceitos e instaurar o plano, como duas asas ou duas nadadeiras. (Deleuze e Guattari, 1992, pp. 57-8).

Vimos com Deleuze e Guattari que o plano de imanência é préconceitual e pré-filosófico. Porém o ser pré-filosófico não o faz não imanente. A palavra imanência acoplada a plano acena a territorialidade, ou ainda melhor, a mundanidade do plano. Ou seja, ele é fabricado do mundo e no mundo. Mesmo o plano de Platão, que fala sempre de um "além mundo", um mundo das idéias, não é um plano de transcendência, pois o seu mundo das idéias é fabricado de modo imanente, na imanência de uma Grécia territorial e geograficamente situada.

Falar de um início intuitivo da filosofia, através do plano de imanência e da possibilidade de uma compreensão não filosófica, mas sensível da mesma, nos abre também um outro caminho: o do erro como ponto fundamental $^{3}$ da filosofia. Não parece possível separar o erro da filosofia, pela própria natureza de sua formação - onde há plano de imanência como começo pré-filosófico e sensível da filosofia, há necessariamente o erro. Este erro aparece na forma de pressupostos subjetivos, aqueles elementos que

\footnotetext{
3 Este "fundamental" deve ser entendido de uma maneira dupla: por um lado representa a idéia de grande importância, e por outro de algo que está no início, no fundamento da própria filosofia. O erro deve ser visto como algo de grande importância para o surgimento e a fundação da filosofia, e também para sua manutenção.
}

(C) Filosofia e Educação (Online), ISSN 1984-9605 - Revista Digital do Paideia 
todos os filósofos tomam como universalmente válidos e aceitos, e dos quais fazem o terreno imanente de sua filosofia:

Por exemplo, Descartes, na segunda Meditação não quer definir o homem como um animal racional, porque tal definição supõe explicitamente conhecidos os conceitos de racional e de animal: apresentando o Cogito como uma definição, ele pretende, pois, conjurar todos os pressupostos objetivos que sobrecarregam os procedimentos que operam por gênero e diferença. Todavia, é evidente que ele não escapa de pressupostos de outra espécie, subjetivos ou implícitos, isto é, envolvidos num sentimento, em vez de o serem num conceito: supõe-se que cada um saiba, sem conceito, o que significa eu, pensar, ser. $\mathrm{O}$ eu puro do $E u$ penso é, portanto, uma aparência de começo apenas porque remeteu todos os seus pressupostos ao eu empírico. (Deleuze, 2006, p. 189).

Desta característica de imprecisão não se pode fugir. O plano de imanência não é ainda filosofia, apenas o solo sobre o qual a mesma cresce. Vejamos agora o último elemento que constitui a filosofia.

\section{Os Personagens Conceituais}

Em uma obra filosófica os conceitos nunca são ditos por seu autor. Não foi Rousseau quem disse toda a riqueza e profundidade de conceitos sobre a educação presentes em $O$ Emílio. Assim como não foi Nietzsche quem disse o eterno retorno pela primeira vez em A Gaia Ciência. Em uma obra filosófica os conceitos são sempre ditos por personagens conceituais. Eles são heterônimos do autor. Isso fica claro nos romances filosóficos de Rousseau e também nos diálogos platônicos e em Nietzsche atinge o apogeu. Porém há ocasiões em que as personagens conceituais não são tão claras e evidentes. Quando lemos A Fenomenologia do Espírito não vemos personagens conceituais como as que encontramos em Rousseau ou Platão. 
Mas há também os casos em que o filósofo não inventa heterônomos: ele é o personagem de si mesmo. Mas é sempre personagem o criador dos conceitos. Como mostrou Foucault em sua conferência intitulada "O que é um autor?", apresentada à Sociedade Francesa de Filosofia em 1969, o autor de um texto é uma ficção, uma função-autor, não uma "mônada subjetiva" que se coloque para além da obra produzida. É essa função-autor trabalhada por Foucault que, no caso da filosofia, Deleuze e Guattari chamam de personagem conceitual. O filósofo René Descartes, por exemplo, foi um personagem criado pelo homem René Descartes e foi esse personagem que criou os seus conceitos. (Gallo, 2003, pp. 56-7).

A filosofia deste modo é quase uma ficção, o que a salva de ser uma ficção total são seus conceitos, seu produto final. Pois no plano de imanência e nas personagens conceituais, ela pouco difere da literatura.

Vejamos agora a possibilidade de enquadrar a Estética Transcendental de Kant neste esquema deleuziano de filosofia.

\section{A estética transcendental}

Antes de analisar parte da filosofia de Kant pelo prisma da filosofia de Deleuze, são necessárias algumas explicações. Como já disse na introdução deste trabalho, esta análise tem duplo objetivo, e em nenhum deles há, realmente, o interesse em discutir se Kant foi ou não filósofo. Apenas relembrando: o primeiro objetivo é mostrar que de acordo com a idéia deleuziana do que é filosofia, Kant pode ser tido como um filósofo de direito. O segundo mostrar que é possível trabalhar com filosofia sem ser filósofo.

Se porém, escolhi um ponto isolado na obra de Kant A Crítica da Razão Pura, e dentro desta um ponto ainda mais específico a Estética Transcendental é também por dois motivos. O primeiro é a pura e simples impossibilidade de abordar toda a obra de Kant, mesmo apenas sua primeira Crítica, por completa em um artigo. O segundo motivo, é que tendo então que fazer uma escolha optei por um dos pontos que considero mais impor-

(C) Filosofia e Educação (Online), ISSN 1984-9605 - Revista Digital do Paideia 
tantes e originais na primeira Crítica, a Estética, talvez comparado apenas com as Antinomias da Razão.

Há ainda um último ponto que precisa ser esclarecido, e cujo esclarecimento já nos colocará nos trilhos da análise deleuziana da Estética Transcendental propriamente dita: destacar uma parte da Crítica da Razão Pura para análise, separada de todas as outras, não será prejudicial ao entendimento da empreitada Kantiana? E também da compreensão de sua filosofia pela teoria deleuziana? A resposta para as duas perguntas é não. Se os conceitos são sempre uma rede interminável de conceitos, não é possível apontar onde se começa e onde se termina, embora seja possível apontar alguns mais importantes que os outros. E a estética em si já apresenta todos os elementos que Deleuze e Guattari apontam como constituintes da filosofia: o plano de imanência, as personagens conceituais e os próprios conceitos.

A empreitada kantiana com sua primeira Crítica tem um sentido bastante claro e definido: Kant pretendia responder uma questão fundamental: por que a metafísica não oferece respostas tão claras, certas e seguras quanto outras disciplinas do conhecimento humano, como a física e a geometria? Foi a partir desta pergunta que Kant fez uma crítica da razão. Porém esta crítica não se constituiu num tribunal da razão, e se voltou muito mais ao sentido original da palavra crítica ${ }^{4}$, o que possibilitou a Kant traçar um limite para a razão pura.

O limite que Kant impôs à razão foi o domínio do transcendental, conceito do qual Kant se apoderou e ressignificou, como veremos adiante. Para provar sua idéia o filósofo alemão criou sua teoria do conhecimento, na qual o conhecimento se forma pela junção de um componente objetivo, material e a posteriori (a matéria do conhecimento) e um outro subjetivo, imaterial e a priori (a forma do conhecimento). E é com a explicação desta teoria do conhecimento que o filósofo inicia a sua Estética Transcendental.

\footnotetext{
${ }^{4}$ A palavra crítica deriva do grego (kritikê) e está ligada à idéia de separação, distinção. Logo o sentido original da crítica kantiana é mostrar o que a razão pode e o que não pode compreender.
} 
Seja de que modo e com que meio um conhecimento possa referir-se a objetos, o modo como ele se refere imediatamente aos mesmos e ao qual todo pensamento como meio tende, é a intuição. Esta, contudo, só ocorre na medida em que o objeto nos for dado; a nós homens pelo menos, isto só é por sua vez possível pelo fato do objeto afetar a mente de certa maneira. A capacidade (receptividade) de obter representações mediante o modo como somos afetados por objetos denomina-se sensibilidade. Portanto, pela sensibilidade nos são dados objetos e apenas ela nos fornece intuições; pelo entendimento, em vez, os objetos são pensados e dele se originam conceitos. (Kant, 1999, p. 71).

Para Kant o problema da metafísica é que nela a razão tenta conhecer algo do qual ela não possui nenhuma intuição, pois são coisas que não afetam nossa sensibilidade. Tentar conhecer sem este pré-requisito nos levará sempre ao erro, por isso a metafísica e seus conteúdos centrais (a origem do mundo, a alma, a liberdade e Deus) são sempre imprecisos. Porém Kant juntou ao elemento material do conhecimento um elemento imaterial e subjetivo, que é a faculdade de formular conceitos inerente ao ser-humano (o intelecto), esta faculdade nos permite dizer da duração de um fenômeno ou da localização de um corpo. Duração e localização implicam dois conceitos fundamentais na Crítica: tempo e espaço. Estes são os dois conceitos centrais da Estética Transcendental.

A própria idéia de uma estética aqui já aponta para os conceitos de tempo e espaço, posto que Kant usou a palavra estética, assim como crítica, em seu sentido clássico ${ }^{5}$, o tempo e o espaço são os dois elementos componentes da estética transcendental, expressão na qual o transcendental, não remete necessariamente a um mundo das idéias ou além deste, mas apenas àquilo que no processo do conhecimento não pertence ao objeto, porém ao sujeito.

\footnotetext{
${ }^{5}$ A palavra estética deriva do grego aisthésis e quer dizer sensibilidade, percepção. E embora fosse anterior à Kant a utilização da palavra estética como estudo do belo, Kant a usou como sinônimo de sensibilidade e/ou sensí vel.
}

(C) Filosofia e Educação (Online), ISSN 1984-9605 - Revista Digital do Paideia 


\section{Os conceitos tempo e espaço}

Tempo e espaço cumprem perfeitamente sua função conceitual. Ambos têm a função simultânea de clarear e solucionar alguns problemas. O problema que a Estética pretende resolver é o problema de toda a Crítica: por que a metafísica não consegue oferecer conhecimentos exatos e seguros como as ciências exatas? Mas para responder tal problema Kant terá que antes especificar como o conhecimento se dá, e é aqui que entram tempo e espaço.

Tempo e espaço são as condições humanas do conhecimento. Se como vimos anteriormente, o conhecimento é a junção de um conceito com uma intuição, tempo e espaço são fundamentais para que haja esta intuição. Tudo aquilo que atinge os nossos sentidos são fenômenos que se dão no tempo e no espaço. Com isso os conceitos além de se proporem a responder um problema, começam a clarear outros, como por exemplo o processo de cognição. Mas eles não se detêm aí, estes mesmos conceitos também serão a linha de frente em uma batalha contra conceitos anteriores que também usaram as palavras tempo e espaço para serem ditos. Deste modo os conceitos de tempo e espaço, em sua função, cumprem ainda um outro papel: eles dão combate aos adversários filosóficos.

[...] Kant contesta com muito vigor qualquer pretensão no sentido de que o espaço e o tempo valem como realidades absolutas, nega que eles possam valer "também independentemente da forma da nossa intuição sensível" e, por fim, nega que eles possam "ser inerentes absolutos das coisas como suas condições ou qualidades”. (Reale e Antiseri, 2003, p. 874-5)

Percebemos por esta citação, e este papel de combate desempenhado pelos conceitos, um outro elemento fundamental em sua identificação: a formação do conceito. Antes de Kant usar os conceitos de tempo e espaço eles tinham uma história, diversos outros filósofos utilizaram as palavras tempo e espaço para significar diversas coisas, também Kant se apoderou delas e lhes deu um novo sentido, este novo sentido, claro, se choca contra os antigos. Qual a idéia mais verdadeira sobre o tempo e o espaço? A de

(C) Filosofia e Educação (Online), ISSN 1984-9605 - Revista Digital do Paideia

Volume 1, Número Especial de lançamento, Outubro de 2009 
Kant, ou, por exemplo, a de Leibniz? Isso não importa, pelo menos não para Deleuze, o que realmente importa é quanto cada um destes conceitos possibilita o pensamento. Se tivéssemos que eleger um critério de validade para um conceito, a possibilitação do pensamento seria ele.

Mas se estes conceitos têm uma história, também compõem uma extensa teia de conceitos relacionais. Vemos ao longo da Estética os conceitos tempo/espaço se relacionarem intensamente com outros conceitos como: sensibilidade, intuição, condição de possibilidade, númeno, fenômeno etc. É participar desta rede de conceitos que torna os conceitos tempo/espaço fortes. Um conceito isolado perde sua força e também é facilmente atacável pelos conceitos rivais.

Vimos até aqui o modo como os conceitos kantianos de tempo e espaço se enquadram perfeitamente na idéia deleuziana de conceito, em especial por seus dois elementos definidores: sua função e formação. Veremos agora como a filosofia de Kant também possui um plano de imanência no qual crescem seus conceitos.

\section{O Plano de Imanência de Kant}

Também em Kant encontramos um plano de imanência, se o plano de imanência é, conforme Deleuze, o pressuposto da filosofia, e sujeito a uma compreensão não conceitual, vamos encontrá-lo na Estética com o nome: de transcendental.

O domínio do transcendental em Kant, como foi dito, não se refere, como em Platão por exemplo, ao mundo das idéias ou a um mundo fora deste, alcançável apenas pelo pensamento, nas palavras do próprio Kant:

Denomino transcendental todo conhecimento que em geral se ocupa não tanto com objetos, mas com nosso modo de conhecimento de objetos na medida em que este deve ser possível a priori. Um sistema de tais conceitos denominar-se-ia filosofia transcendental. (Kant, 1999, p. 65).

Reale e Antiseri explicam a passagem acima nos seguintes termos:

(C) Filosofia e Educação (Online), ISSN 1984-9605 - Revista Digital do Paideia 103

Volume 1, Número Especial de lançamento, Outubro de 2009 
Muitos acharam essa concepção muito obscura e alguns contemporâneos a subentenderam grosseiramente. Mas, levando em conta o que já dissemos, é possível esclarecê-la com facilidade: os "modos de conhecer a priori do sujeito" são a sensibilidade e o intelecto; portanto, Kant chama de transcendentais os modos ou as estruturas da sensibilidade e do intelecto. Essas estruturas, portanto, enquanto tais, são a priori, precisamente porque são próprias ao Sujeito e não do objeto, mas são estruturas de tal natureza que representam as condições sem as quais não é possível nenhuma experiência de nenhum objeto. O transcendental, portanto, é a condição da cognoscibilidade dos objetos (a condição da intuibilidade e da pensabilidade dos objetos). (Reale e Antiseri, 2003, p. 872).

Se o transcendental é aquilo que escapa ao objeto e se encontra apenas no sujeito, ele não é passível de análise, pois o sujeito cognoscente não pode ser, ao mesmo tempo, sujeito e objeto do conhecimento, pois haveria aí uma contradição lógica ${ }^{6}$. Vale ainda ressaltar que no fundo, para Kant, nada pode ser realmente conhecido pelo homem em sua essência, tempo e espaço não são a condição para o conhecimento das coisas em si, mas apenas como elas se mostram à sensibilidade humana e podem ser conceituada por seu intelecto.

O transcendental aqui, embora tenha um apelo humano, foge à capacidade humana de compreensão e domínio, não está sujeito a discussões e análises, ele deve ser aceito como a condição sem a qual os conceitos tempo/espaço não podem aparecer.

Note-se porém que ao nomear o seu plano de imanência como uma filosofia transcendental, Kant não o torna menos imanente por isso. A sua transcendência é apenas palavrório, ela é construída com o que há de mais imanente possível: as palavras e o corpo, digo o corpo porque se o que é

\footnotetext{
${ }^{6}$ Para Kant um homem pode ser objeto de conhecimento de si próprio, mas este conhecimento não seria do que o homem é em si, mas apenas do homem enquanto fenômeno, como ele aparece ao sentido de compreensão interior, o tempo.
}

(C) Filosofia e Educação (Online), ISSN 1984-9605 - Revista Digital do Paideia 
transcendente é aquilo que pertence apenas ao sujeito, este sujeito é corpo, ou ao menos não pode prescindir de um.

Vejamos agora o modo como os personagens conceituais aparecem na Estética Transcendental e o duplo papel que exercem nesta parte da Crítica.

\section{Os Personagens Conceituais}

Como dito anteriormente, alguns filósofos apresentam seus personagens conceituais de um modo bastante claro, é o caso de Nietzsche ou Rousseau, porém em muitos casos estes personagens conceituais não aparecem, poderíamos chamá-los então de personagens conceituais ocultos. Este é o caso da Estética Transcendental de Kant. Encontramos nela pelo menos dois personagens conceituais ocultos.

Como afirma Gallo em citação neste trabalho (p. 9), muitas vezes um filósofo cria a si mesmo na qualidade de personagem para dizer seus conceitos em sua obra. Deste modo não é o homem Kant quem diz os conceitos da Estética, porém o personagem conceitual "filósofo Kant" é quem o faz. É da boca deste personagem que vertem os conceitos. Porém não é este o único personagem conceitual da obra.

A primeira Crítica de Kant tem um caráter combativo bastante acentuado, embora também bastante polido. O livro causa até suspense quando encerra dizendo que não podemos compreender os elementos metafísicos pelas vias da razão. Para um filósofo iluminista, uma crítica destas à razão é bastante incomum, o problema só foi resolvido quando em sua segunda Crítica Kant reabilitou a razão, falando então de uma razão prática.

Ao longo de toda a primeira Crítica, vemos o personagem conceitual oculto, Kant, se debater contra outros tantos personagens conceituais, estes também ocultos, e que falam as vozes das idéias que Kant critica e ataca, uma hora é o personagem conceitual oculto Descartes, outra é Leibniz e tantos outros. Porém em Kant a personagem conceitual Descartes, por exemplo, não é a personagem conceitual Descartes, que o filósofo francês 
René Descartes criou em suas próprias obras. Como em Nietzsche, o Kant personagem conceitual, para o qual o filósofo alemão sempre reservou bons apelidos, não é o mesmo Kant personagem conceitual oculto que aparece na Crítica.

Então o que vemos na estética são conceitos (tempo/espaço), nascendo de um plano de imanência (transcendência) sendo ditos por um personagem (personagem conceitual oculto Kant) combatendo e vencendo outros tantos conceitos, ditos por outros tantos personagens conceituais ocultos.

\section{Considerações Finais}

Como vimos ao longo do texto, a filosofia, para Deleuze, é constituída por uma tríade: o conceito, o plano de imanência e os personagens conceituais. Obviamente estes três elementos podem servir como critério de análise para diversos pensamentos e teorias na área de estudo das ciências humanas, como fizemos aqui com a Estética Transcendental, parte componente da Crítica da Razão Pura de Kant.

Em momento algum se teve a pretensão de duvidar do status filosófico de Kant ou de sua primeira Crítica e sua parte aqui estudada, a Estética Transcendental. Porém o artigo permite uma análise técnica, é uma demonstração de como os "pré-requisitos" propostos por Deleuze para que uma teoria seja filosófica, podem ser usados como categorias de análise.

Somente agora podemos analisar ou buscar responder uma pergunta bastante importante para este trabalho: é possível lidar com a filosofia sem ser filósofo? Esta pergunta possibilita uma segunda: este artigo é filosófico?

A resposta para a primeira pergunta é sim. É possível trabalhar com a filosofia sem ser filósofo, ou sem fazer filosofia. Este é o trabalho do professor de filosofia, do especialista em filosofia. Eles fazem o que tentei fazer neste trabalho: analisar um problema filosófico e torná-lo mais claro, porém 
isso não implica, necessariamente, no surgimento dos três elementos constituintes da filosofia.

O esforço neste texto não é para criar filosofia, produzindo novos conceitos, nomeando um plano de imanência e criando personagens conceituais. O esforço é outro, porém não menor ou menos importante: buscar uma "filosofia aplicada", ou seja, tomar conceitos já existentes e usá-los como chaves de análise e explicação de diversos problemas, ou mesmo de outras teorias, porém sem necessariamente, acrescentar algo de novo aos conceitos tomados de algum filósofo.

A resposta para a segunda pergunta é não, este trabalho não é filosófico, isso claro, tomando o termo "filosófico" como algo próprio da filosofia, e esta, segundo o pensamento de Deleuze. Não ser filosófico não diminui sua importância acadêmica, pois muitas teorias precisam ser melhor explicadas e elucidadas, papel dos professores e técnicos em filosofia, o que também não os impede de serem, em algum momento, filósofos.

É difícil dizer qual o melhor caminho para tornar-se filósofo, mas a análise da biografia de alguns filósofos, em especial os modernos e contemporâneos nos mostrará claramente que antes de serem filósofos, foram professores de filosofia, antes de criarem seus próprios conceitos, enraizados em um plano de imanência e ditos por personagens conceituais, estes filósofos exploraram o pensamento dos seus antecessores, buscaram explicitar, para os outros (alunos e colegas de profissão) e para si mesmos estes conceitos, só então, muitas vezes na tentativa de combater estes conceitos, começaram sua própria produção: isso aconteceu com Kant e com Deleuze, mas também com Hegel, Schopenhauer, Nietzsche, Heidegger, Foucault e tantos outros.

Quando Deleuze submete o ser ou não ser filosofia à criatividade e produção do novo, ele necessariamente empurra a filosofia para o caminho da multiplicidade: fazer filosofia é criar o novo, o múltiplo o diverso. É enfrentar os adversários conceituais e ampliar o pensamento. 


\section{Referências Bibliográficas}

DELEUZE, Gilles. A Filosofia Crítica de Kant. Trad. Germiniano Franco. Lisboa: Edições 70, 1963.

DELEUZE, Gilles. Lógica do Sentido. Trad. Luiz Roberto Salinas Fortes. São Paulo: Perspectiva, 2006.

DELEUZE, Gilles e GUATTARI, Félix. O que é a Filosofia? Trad. Bento Prado Jr. e Alberto Alonso Muñoz. Rio de Janeiro: Ed. 34, 1992.

GALLO, Silvio. Deleuæe \& a Educação. Belo Horizonte: Autêntica, 2003.

HARDT, Michael e DELEUZE, Gilles. Um Aprendizado em Filosofia. Trad. Sueli Cavendish. São Paulo: Ed. 34, 1996.

HEIDEGGER, Martin. Que é uma coisa? Doutrina de Kant dos princípios transcendentais. Rio de Janeiro: Edições 70. s. d.

HEIDEGGER, Martin. Os Conceitos Fundamentais da Metafísica: mundo, finitude, solidão. Trad. Marco Antônio Casanova. Rio de Janeiro, Forense Universitária, 2003. $1^{\text {a }}$ edição.

HERRERO, Francisco Javier. Religião e História em Kant. Trad. José A. Ceschia. São Paulo: Loyola, 1991.

Kant, Immanuel. A Religião nos Limites da Simples Raðãa. Trad. Artur Mourão. Lisboa: Edições 70, s.d.

KANT, Immanuel. Crítica da Razão Pura. Trad. Valério Rohden e Udo Baldur Moosburger. São Paulo: Editora Nova Cultural, 1999 (Os Pensadores).

NIETZSCHE, Friedrich Wilhelm. Genealogia da Moral: uma polêmica. Trad., notas e posfácio: Paulo César de Souza. São Paulo: Companhia das Letras, 1998.

PASCAL, GEORGES. Compreender Kant. Trad. e introdução: Raimundo Vieira. Petrópolis (RJ): Vozes, 2005.

REALE, Giovanni. História da filosofia: do Humanismo a Kant. São Paulo: Paulus, 1990.

(C) Filosofia e Educação (Online), ISSN 1984-9605 - Revista Digital do Paideia 